\title{
Cutaneous Squamous Cell Carcinoma with Perineural Invasion: Report on Eight Cases and Review of the Literature
}

\author{
Maurice Verburg ${ }^{a, d}$ Martin Lang ${ }^{b, d}$ Michael Mühlstädt ${ }^{f} \quad$ Annette Klein $^{c, e}$ \\ Jürgen Schauber ${ }^{d}$ Elke C. Sattler ${ }^{d}$ Christian Kunte ${ }^{c, d}$ \\ aDepartment of Dermatology, MC Zuiderzee, Lelystad, The Netherlands; ${ }^{b}$ Practice for Dermatology, \\ Stockmeier M.D., Ingolstadt, ' Department of Dermatology and Dermatosurgery, Artemed Hospital, Munich, \\ ${ }^{\mathrm{d}}$ Department of Dermatology and Allergology, Ludwig Maximilian University, Munich, and ${ }^{\text {Department of }}$

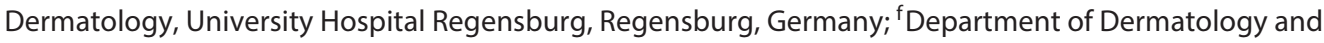 \\ Venereology, University Hospitals of Geneva, Geneva, Switzerland
}

\section{Key Words}

Squamous cell carcinoma - Perineural invasion .

Radiotherapy $\cdot$ Mohs surgery $\cdot$ Skip lesions

\begin{abstract}
Background: Perineural invasion (PNI) in cutaneous squamous cell carcinoma (SCC) is considered to be a negative prognostic factor. A lot of uncertainty remains regarding the classification, diagnosis, treatment and prognosis of SCC with PNI. Objective: To describe typical courses of SCC with PNI and associated findings in order to suggest an optimized diagnostic and therapeutic approach. Methods: We present eight cases of SCC with PNI, considering patient and tumor characteristics, histology, treatment and clinical course regarding local recurrence and metastasization. Results: SCC patients with PNI have a higher rate of local recurrences and greater risk for metastasization than SCC patients without PNI. Age ranged from 68 to 77 years, 6 patients were male and 2 female, with all tumors localized on the head. Three patients had chronic lymphocytic leukemia. Conclu-
\end{abstract}

\section{KARGER 125}

(c) 2014 S. Karger AG, Basel

$1018-8665 / 14 / 2302-0135 \$ 39.50 / 0$

E-Mail karger@karger.com

www.karger.com/drm sion: Based on the data of this series and the current literature, we make suggestions for better diagnostic and therapeutic management.

(c) 2014 S. Karger AG, Basel

\section{Introduction}

Squamous cell carcinoma (SCC), along with basal cell carcinoma, is one of the most common non-melanoma skin cancers. Actinic keratosis is considered as a precursor lesion of SCC. The treatment of choice is usually excision. As the diagnosis is often established at an early stage, rates of local recurrences or metastases are low. The risk of metastases in non-melanoma skin cancer $(2-3 \%$ in SCC, $<0.01 \%$ in basal cell carcinoma) is much smaller compared to malignant melanoma $[1,2]$. However, it does occur. Indicators of poor prognosis for local recur-

E.C. Sattler and C. Kunte contributed equally to this work.
Christian Kunte

Department of Dermatology and Dermatosurgery Artemed Hospital

Mozartstrasse 14 a - 16, DE-80336 Munich (Germany)

E-Mail christian.kunte@artemed.de 
rences and metastatic disease in SCC are tumors $>2 \mathrm{~cm}$ in diameter, tumor thickness $\geq 2 \mathrm{~mm}$, poorly differentiated tumors, invasion into or below the reticular dermis, areas of previous irradiation, immunosuppression and - more recently acknowledged - perineural invasion (PNI) [35]. PNI was first described a century ago as the spread of tumor cells along the nerves just beneath the perineurium [6]. During the last two decades an increasing number of reports of PNI in SCC have been published. This tumor spread along the loose connective tissue of the perineurium is unpredictable and difficult to treat. Invasion of tumor cells into a cranial nerve may lead to invasion into the brain stem. Unfortunately, there is a lot of uncertainty regarding the classification, diagnosis, treatment and prognosis of SCC with PNI [7]. We describe eight cases of SCC with PNI and describe our reasoning on establishing the diagnosis and treatment of this entity, reviewing the current literature.

\section{Case Presentation (table 1)}

\section{Patient 1}

A 75-year-old Caucasian man consulted our clinic for a recurrent SCC on the forehead. Physical examination revealed multiple erythematous plaques with yellow crusts of $3 \times 3 \mathrm{~cm}$ on the left side of the forehead. As the patient also suffered from chronic lymphocytic leukemia (CLL), the enlarged palpable cervical lymph nodes were sonographically assessed as lymph nodes consistent with the known CLL. Histopathology of the tissue from the left side of the forehead revealed SCC with scar tissue and clear excision margins. One year later the patient presented with a recurrent tumor of $1.5 \times 1.5 \mathrm{~cm}$ again on the left side of the forehead (fig. 1a). On clinical evaluation the patient had an impairment of the frontal branch of the facial nerve (clinical PNI, cPNI). Histology showed an incompletely removed SCC with PNI; a metastasis could not be excluded. One month later we saw the patient for re-excision. Intraoperatively the tumor could be followed down to the left orbital rim (fig. 1b). Excision showed again an incompletely excised SCC with a locoregional metastasis with PNI. The thickness of the nerves involved was $0.08-0.15 \mathrm{~mm}$ at first and $0.25-0.35 \mathrm{~mm}$ at second excision. Staging showed no evidence of intracranial metastases (PET scan and MRI). Due to the aggressive behavior of the tumor we consulted the oral and maxillofacial surgeons. They performed two re-excisions along the supraorbital nerve. The patient developed metastases on the left upper eyelid with infiltration of the left orbit and in the area of the sinus cavernosus. This resulted clinically in upper eyelid ptosis and the patient complaining of double vision. He received radiotherapy (RT) for the metastasis of the left orbit (48.0 Gy in 6 fractions). The patient died 16 months after diagnosis of SCC with cPNI of unknown cause.

\section{Patient 2}

A 70-year-old Caucasian man presented with a recurrent SCC on the right temple with previous incomplete excision. Physical examination revealed a $5 \times 5 \mathrm{~cm}$ ulcerated and hemorrhagic tumor
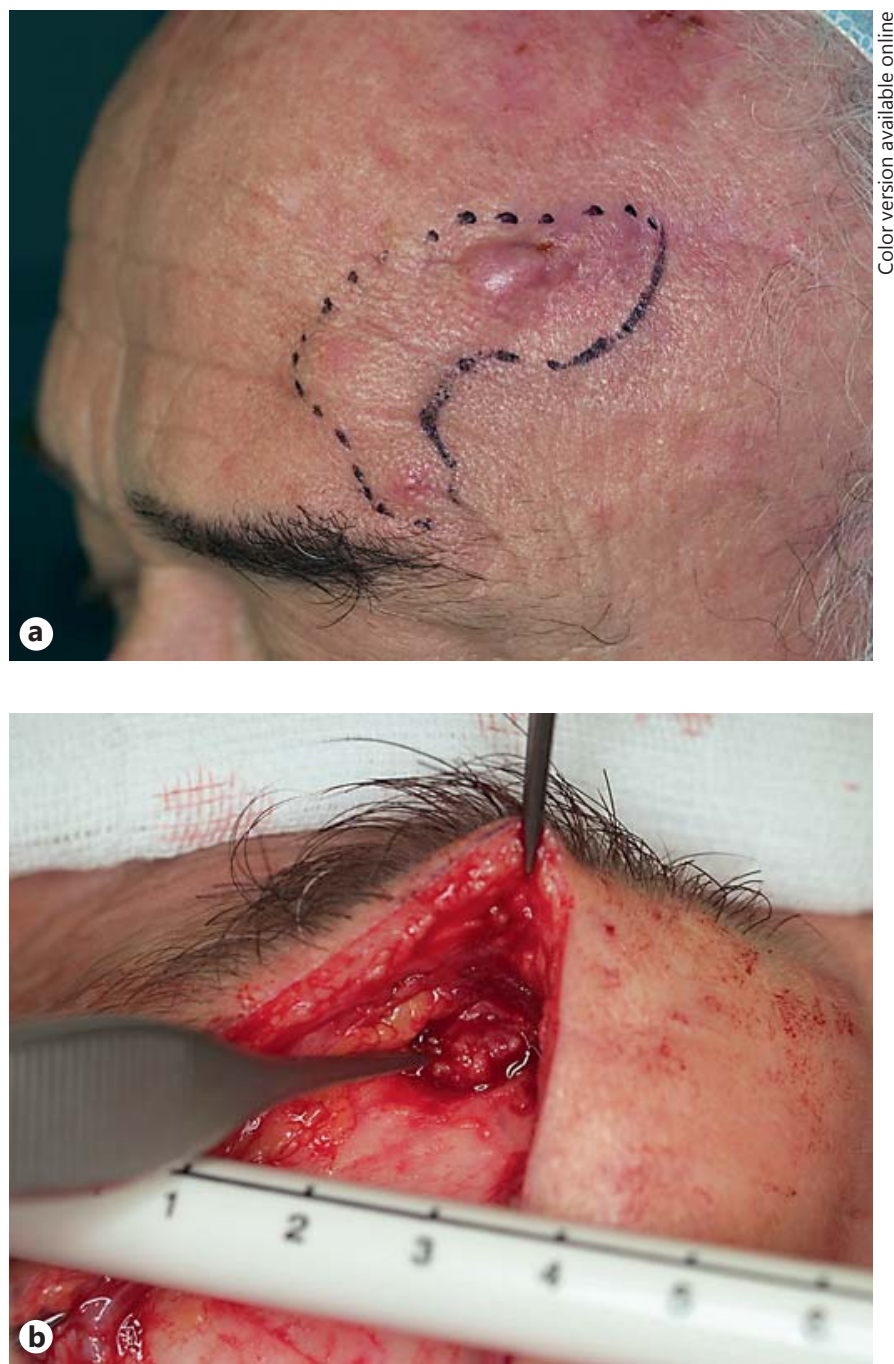

Fig. 1. a A 75-year-old Caucasian male with a recurrent SCC on the left forehead. Excision showed an incompletely removed SCC with PNI, possibly a metastasis. b Intraoperatively the tumor could be followed down to the left orbital rim. The tip of the forceps points to the SCC surrounding the supraorbital nerve. Excision showed an incompletely excised SCC with locoregional metastasis with PNI.

with no clinical signs of nerve involvement. No palpable head or neck lymphadenopathy was identified. Our first excision was again incomplete, re-excision was histologically complete. However, 2 months later the patient presented with a recurrence. Again we excised the tumor and histology showed free margins. Three months later the patient presented again with a recurrence and an additional periauricular tumor on the right side. Histology of both excisions revealed completely removed SCCs. A CT scan showed a local recurrence on a large area of the scalp. Ultrasound of the cervical lymph nodes and of the abdomen showed no evidence of metastases. Given the aggressive behavior of this tumor and the presence of PNI, the patient was referred for adjuvant RT, which 
he completed. Four months later he presented with a $2 \mathrm{~cm} \mathrm{SCC} \mathrm{on}$ the scalp, which we excised with histologically free margins. Because of the multiple recurrences, status after broad excisions with split skin grafts and status post adjuvant RT, the patient was referred to the oral and maxillofacial surgeons for further care and was then lost to follow-up.

\section{Patient 3}

A 68-year-old Caucasian woman presented to our clinic with an incompletely removed SCC on the forehead that had been previously treated elsewhere using serial excisions [4] with signs of clinical nerve involvement. The patient had lymphadenopathy of unknown origin; ultrasound did not show any evidence of metastases. We completely removed the ulcerated SCC that revealed PNI with a thickness of nerves involved of $0.07-0.13 \mathrm{~mm}$. Two months later a recurrent tumor was again excised with histologically free margins and again showed a SCC without PNI. 20 months later the patient had to undergo a large surgery with large excision, bone removal and a large flap to cover the defect due to a relapse of the tumor. Multiple postoperative complications occurred with a stroke and the patient is currently being treated at an intensive care unit.

\section{Patient 4}

A 68-year-old Caucasian man presented to our clinic with an incompletely removed SCC with PNI and lymphangiosis carcinomatosa along the scar on the left temple. We performed a re-excision with a safety margin of $1.0 \mathrm{~cm}$. PET and CT scan of the head and ultrasound of the lymph nodes showed no evidence of metastases. Given the aggressive behavior of the tumor the patient received adjuvant RT (60.0 Gy). He did not develop a relapse during the 3-year follow-up period.

\section{Patient 5}

A 77-year-old Caucasian woman presented with a recurrent SCC on the forehead. Physical examination showed three nodules at the site of the first excision that had previously been closed by skin graft (fig. 2a). They had been rapidly and progressively growing for 1 month. We excised these lesions and 3D histology showed SCCs with PNI. One month later the patient presented with two new tumors of $1 \times 2 \mathrm{~cm}$ at the margin of the latest scar (fig. $2 \mathrm{~b}$ ). Histology again showed a SCC with PNI. Ultrasound revealed echo-poor cervical, preauricular and nuchal structures compatible with cutaneous and lymph node metastases. MRI of the head and neck showed multiple pathological lymph nodes along the nerves, while staging of the thorax and abdomen using ultrasound, X-ray and CT revealed no evidence of metastases. Given the aggressive behavior of the tumor the ear-nose-throat surgeon was consulted. He performed extensive excision including neck dissection and referred the patient for adjuvant $\mathrm{RT}$. During radiation new tumors developed at the border of the radiation field which in turn had to be extended. The tumors regressed. However, the patient developed new and extended metastases 3 months later and was again treated by radiation. This time the tumors did not regress during therapy. The patient presented to our clinic with an ulcerated tumor of $10 \mathrm{~cm}$ in diameter on the left temple. Histopathology again showed local recurrence of the aforementioned SCC. In addition multiple nodules of up to $1.5 \mathrm{~cm}$, consistent with metastases, had developed. The patient refused further staging and died a few months later, 2 years after the first diagnosis of SCC with PNI.

Cutaneous Squamous Cell Carcinoma with Perineural Invasion
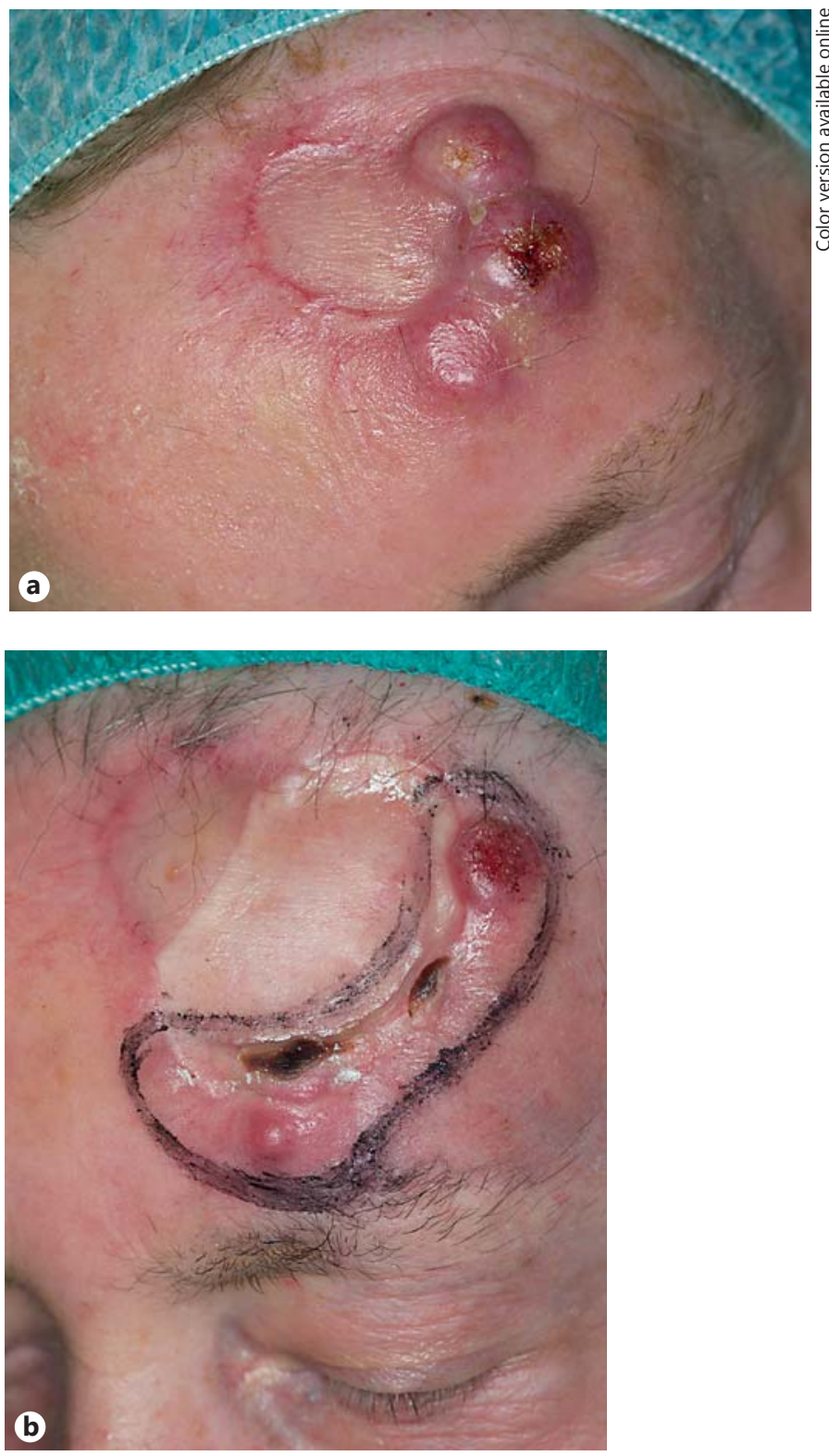

Fig. 2. a A 77-year-old Caucasian with recurrence of a SCC (excised elsewhere) on/at the border of the defect. Excision was complete (3D histology). b One month later the patient presented with two new tumors of $1.0 \times 2.0 \mathrm{~cm}$ at the edge of the scar. Excision showed a completely removed SCC with PNI (3D histology).

\section{Patient 6}

A 69-year-old man presented to our clinic with a $1.5 \times 1.5 \mathrm{~cm}$ erythematosquamous plaque on the right parietal region, with clinical signs of nerve involvement. No lymph nodes were palpable on the head or the neck. Histology identified a SCC with PNI and margins free of tumor. Fifteen months later he presented with new nodules in the surgical area that had developed within 4 weeks. Physical examination revealed a tumor of $2 \mathrm{~cm}$ on the right side of 
Table 1. Patient characteristics

\begin{tabular}{|c|c|c|c|c|c|c|c|c|c|c|}
\hline $\begin{array}{l}\text { Patient } \\
\text { No. }\end{array}$ & $\begin{array}{l}\text { Age at } \\
\text { excision }\end{array}$ & Sex & $\begin{array}{l}\text { Histological } \\
\text { subtype, } \\
\text { differentiation }\end{array}$ & Location & $\begin{array}{l}\text { Primary/ } \\
\text { recurrent, } \\
\text { thickness of } \\
\text { infiltrated nerve }\end{array}$ & $\begin{array}{l}\text { Clinical } \\
\text { tumor size } \\
\left(\mathrm{cm}^{2}\right)\end{array}$ & $\begin{array}{l}\text { Exci- } \\
\text { sions } \\
(n)\end{array}$ & $\begin{array}{l}\text { Staging } \\
\text { for } \\
\text { metastasis }\end{array}$ & RT & $\begin{array}{l}\text { Under- } \\
\text { lying } \\
\text { disease }\end{array}$ \\
\hline 1 & 75 & $\mathrm{~m}$ & $\begin{array}{l}\text { poorly } \\
\text { cPNI }\end{array}$ & $\begin{array}{l}\text { left } \\
\text { forehead }\end{array}$ & $\begin{array}{l}\text { recurrent } \\
0.08-0.15 \mathrm{~mm}\end{array}$ & 9 & 6 & + & + & CLL \\
\hline 3 & 68 & $\mathrm{f}$ & $\begin{array}{l}\text { moderately } \\
\text { cPNI }\end{array}$ & forehead & $\begin{array}{l}\text { primary* } \\
0.07-0.13 \mathrm{~mm}\end{array}$ & $*$ & 5 & + & - & \\
\hline 4 & 68 & $\mathrm{~m}$ & $\begin{array}{l}\text { poorly } \\
\text { aPNI }\end{array}$ & $\begin{array}{l}\text { left } \\
\text { temple }\end{array}$ & $\begin{array}{l}\text { primary* } \\
0.1 \mathrm{~mm}\end{array}$ & $*$ & 1 & - & + & \\
\hline 7 & 77 & $\mathrm{~m}$ & $\begin{array}{l}\text { poorly } \\
\text { aPNI }\end{array}$ & $\begin{array}{l}\text { parietal } \\
\text { right }\end{array}$ & $\begin{array}{l}\text { recurrent } \\
0.3 \mathrm{~mm} / \\
\text { multiple nerves }\end{array}$ & 9 & 5 & + & - & CLL \\
\hline 8 & 69 & $\mathrm{~m}$ & $\begin{array}{l}\text { poorly } \\
\text { cPNI }\end{array}$ & $\begin{array}{l}\text { left } \\
\text { cheek }\end{array}$ & $\begin{array}{l}\text { primary* } \\
0.1 \mathrm{~mm}\end{array}$ & $*$ & 3 & + & - & CLL \\
\hline
\end{tabular}

Thickness of nerve measurements were performed on the tissue that was gathered on the first excision at our department. ${ }^{*}$ Removed elsewhere.

the forehead, and an infiltrative $2 \times 2 \mathrm{~cm}$ plaque with hyperkeratosis on the skull. Histology described an incompletely removed SCC on the right side of the forehead. Complete resection of the tumor was not possible, although the periosteum of the right frontal region had been included. CT and PET scans showed signs of scar tissue or residual tumor cells, but no evidence of metastases. Given the aggressive behavior of the tumor the patient was referred to the oral and maxillofacial surgeons and to the neurosurgeons, who performed radical resection down to the level of the tabula externa, which again was incomplete. As no further excision was possible, RT was added with a cumulative dose of $66.0 \mathrm{~Gy}$. During the follow-up period of 11 months the patient did not show any relapse.

\section{Patient 7}

A 77-year-old man with a $3 \times 3 \mathrm{~cm}$ exophytic and ulcerated erythematous tumor was referred to our clinic. Histology revealed a poorly differentiated SCC $6.5 \mathrm{~mm}$ in thickness with PNI. Another four excisions were necessary to achieve tumor-free borders, creating a defect of approximately $20 \times 30 \mathrm{~cm}$; a mesh graft was used to cover the defect. Untreated CLL had been known for 10 years. Ultrasound of the neck showed no pathologically enlarged lymph nodes. During the follow-up period of 8 months there was no evidence of relapse or metastases.

\section{Patient 8}

The patient was a 69-year-old man. Six months prior to referral a moderately differentiated SCC of $1.6 \mathrm{~cm}$ in thickness on the left cheek had been incompletely excised at an outside facility. Five months post intervention an ulceration had developed in the middle of the scar. Biopsy revealed diffuse and infiltrative SCC with PNI. Upon examination the patient showed weakness of the branches of the facial nerve on the left side, either as a result of surgery or of PNI. We excised the area $(5.5 \times 4.5 \mathrm{~cm})$ reaching into Bichat's fat pad and the mimic muscles. Ultrasound of the neck showed a suspicious lymph node on the left side. Since the tumor could not be excised completely in all directions, the patient was referred to the oral and maxillofacial surgeons for extensive excision and neck dissection which was incomplete, followed by adjuvant RT up to $65.5 \mathrm{~Gy}$. Follow-up of 6 weeks since the end of RT has not revealed any signs of relapse. The patient is known to have CLL and had previously been treated three times by chemotherapy.

\section{Discussion}

Our cases follow the typical characteristics for SCC with PNI: older patients with recurrent and/or multiple incompletely excised SCCs (tables 1,2) [2, 8-17]. Most of 
Table 2. Previous publications of SCC with PNI

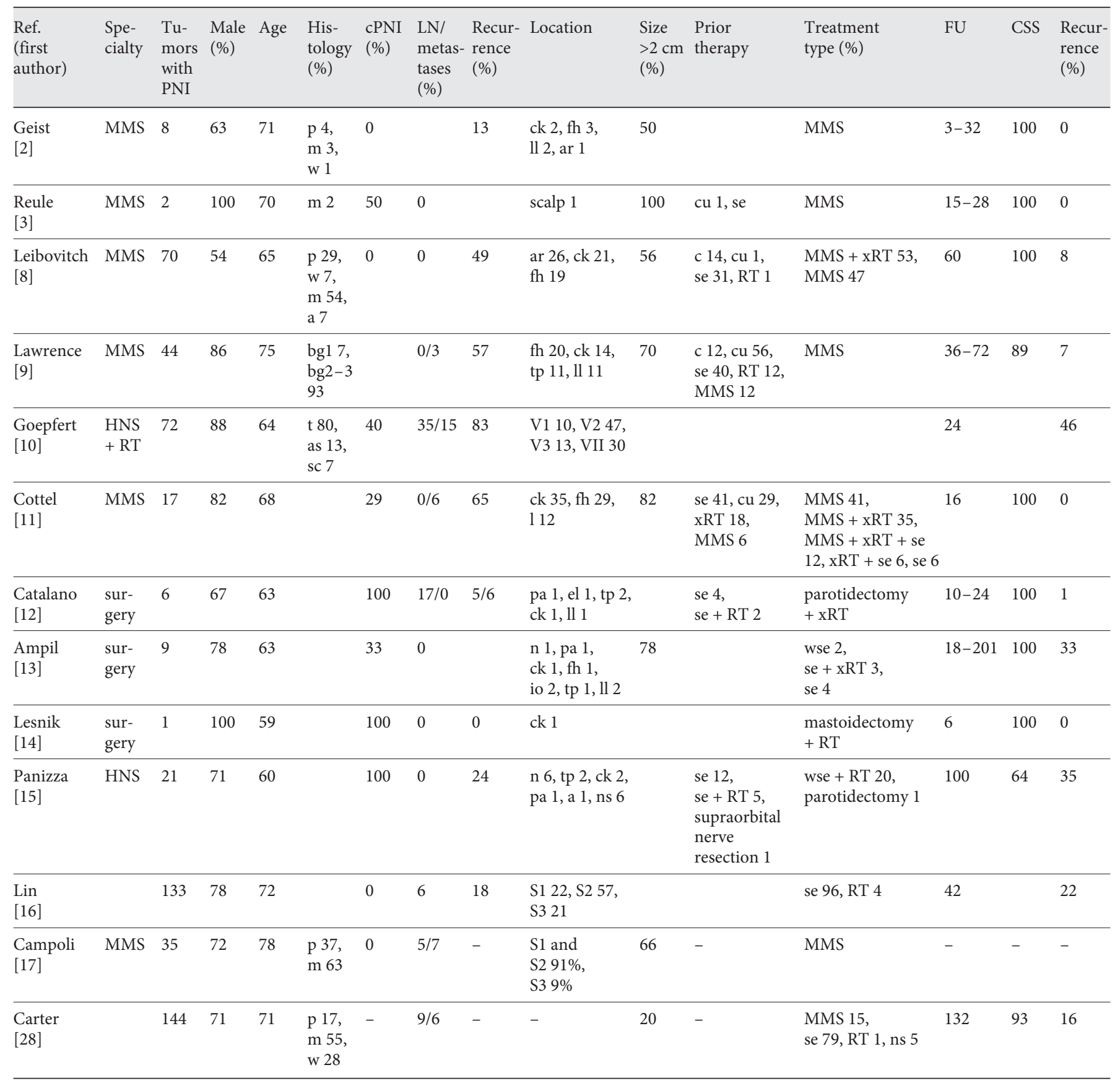

$\mathrm{a}=$ Acantholytic; $\mathrm{ar}=$ auricular; as = adenosquamous; $\mathrm{bg}=$ Broders' classification grade; $\mathrm{c}=$ cryosurgery; $\mathrm{ck}=\mathrm{cheek}$; CSS = cause-specific survival; $\mathrm{cu}=$ curettage; $\mathrm{fh}=$ forehead; $\mathrm{FU}=$ follow-up period (months); HNS = head and neck surgery; io = infraorbital; $1=$ lip; $1 \mathrm{l}=$ lower lip; $\mathrm{LN}=$ lymph nodes; $\mathrm{m}=$ moderately differentiated; $\mathrm{n}$ = nodulocystic; $\mathrm{ns}$ = not specified; $\mathrm{p}=$ poorly differentiated; $\mathrm{pa}$ = preauricular; $\mathrm{S} 1$ = site 1 : forehead, eyebrow, upper eyelid, inner canthus, lower eyelid, nose, nasolabial sulcus; S2 = site 2: scalp, preauricular, parotid, mandible, lower lip, chin, temple, upper lip, cheek; S3 = site 3: other (outside head and neck); sc = spindle cell; se = surgical excision; $\mathrm{t}=$ typical; $\mathrm{tp}=$ temple; V1 = nervus ophthalmicus; V2 = nervus maxillaris; V3 = nervus mandibularis; VII = nervus facialis; $\mathrm{w}=$ well differentiated; wse $=$ wide surgical excision; $\mathrm{xRT}=$ adjuvant $\mathrm{RT}$. 
our patients were 60 years or older, and an average of four excisions were necessary for complete removal. This is consistent with the current literature. However, the literature on SCC with PNI is scarce. Recently an incidence of $4.6 \%$ was found in 753 cutaneous SCC cases [17]. The histological subtype described in our series was mostly of poor or moderate differentiation, also in concurrence with previous publications (table 2). The tumors in our series presented only in the head and neck region, just as described in the literature. All patients presented with a tumor size of $>2 \mathrm{~cm}$. We mainly referred them (next to adjuvant RT) to the oral maxillofacial surgeon for wide excision and lymph node dissection - more frequently than described in the literature.

There are two groups of patients described in the literature. One group consists of patients with cPNI, who suffer from clinical symptoms of damaged nerves, and the other group comprises patients without neurological symptoms (asymptomatic PNI, aPNI). aPNI is an incidental finding on histological examination. Most cases described in the literature are cPNI (table 2). Regarding the prognosis it is important to differentiate between these two groups. Patients with cPNI have a higher rate of recurrence and metastases compared to patients with aPNI $[3,7]$. Unfortunately, these two populations are often combined and not clearly distinguished in most publications. Also the definition of cPNI is not used uniformly. Some authors define cPNI as a patient with clinical neurological symptoms, while others rely on positive findings on imaging. In our patients four out of eight presented with cPNI on clinical investigation. Furthermore, there are many reports of skin carcinoma in general (without differentiation of type) and PNI. They describe that most tumors are SCCs and few are basal cell carcinomas, but a clear distinction is rarely made. As seen in table 2, most patients are male, with a mean age of 60 70 years. The predominant histological subtype (if described) is moderate to poor differentiation. One study describes lymph node metastases to be present in $35 \%$ of cases [10]. In other studies this number is lower; however, fewer patients were included in these studies. A large number of SCCs with PNI are recurrent tumors (13-83\%, table 2). First-line therapy was standard surgical excision in most cases, and to a lesser extent cryotherapy, electrocautery and curettage or shave excision. In most cases tumor size was $>2 \mathrm{~cm}$, but smaller tumors are also mentioned (table 2). The risk of metastases increases with tumor thickness. We assume that the risk of cPNI increases with tumor thickness as well as with tumor diameter $(>2 \mathrm{~cm})$. This requires further investigation.
There are three diagnostic instruments to identify SCC with PNI: (1) patient history with neurological examination to diagnose neuropathy/nerve involvement, (2) histological evaluation of specimens and (3) radiographic imaging. The physician should ask about facial pain, dysesthesia, tingling, burning and shooting pain or formication. Increasing numbness or pain is an important signal for nerve involvement. Physical examination should include a neurological status focused on motor impairments (facial weakness, ptosis, diplopia, blurred vision, ophthalmoplegia, fasciculations). Given the $24 \%$ of lymph node metastases in PNI in the study of Goepfert et al. [10], we think that a thorough lymph node examination using ultrasound should be mandatory. Tumor cells may only show subtle signs of atypia. Even perineural inflammation can be a sign of PNI and further research concerning histopathological features of PNI is necessary. Green et al. [18] stated that Mohs frozen tissue sections would be better to identify SCC with PNI than paraffin-embedded tissue sections. Patients with cPNI have reduced alpha B-crystallin staining; whether this is also true for aPNI is not known yet [19]. p75 NGFR staining (a nerve growth factor receptor) could also offer a clue in PNI [20]. However, perivascular cells, basal cells of the epidermis, basal layers of hair follicles and sweat glands are also p75 NGFR-positive, so this staining is not highly specific. S100 staining (marking the axon) can also be helpful. The use of both stainings is advisable. Laminin 5 and plasminogen activator inhibitor 1 are also described as staining possibilities. A limitation may be skip lesions. Skip lesions are (1) processing artefacts, (2) inflammation with tumor regression or (3) a true skipping of regions of nerves as single tumor cells travel along the length of a nerve, making false-negative histological examination possible [3]. Recent investigations confirm former data that skip lesions in fact do not really exist [21]. Furthermore, Ross et al. [22] described that the chance of metastasis increases with the diameter of the involved nerve $(>0.09 \mathrm{~mm})$. Lin et al. [16] noted that nerves affected up to $1 \mathrm{~mm}$ did not affect survival, whereas infiltration of thicker nerves did. In our patients no clear association between thickness of infiltrated nerves and prognosis could be seen, probably due to the small number of patients. Especially in patients 1 and 3 with worse outcome we could not see any rule for course of their disease. In patient 1 the thickness of nerves involved was $0.08-0.15$ $\mathrm{mm}$ at first excision and developed to $0.25-0.35 \mathrm{~mm}$ at second excision, associated with the growth of the tumor along the lateral branch of the supraorbital nerve, which might be an explanation for the progression of the disease. On the other hand in patient 3 the thickness of the nerves
Verburg/Lang/Mühlstädt/Klein/ Schauber/Sattler/Kunte 
involved at first surgery was $0.07-0.13 \mathrm{~mm}$ and there was no evidence of nerve involvement at second excision. If large nerves $(\geq 1 \mathrm{~mm})$ are invaded, additional risk factors like a diameter of $\geq 2 \mathrm{~cm}$, infiltration of subcutaneous fat and multiple nerve involvement may be found, as well as an increased risk of nodal metastases [23].

Treatment of SCC with PNI is a challenge. There are no randomized controlled trials comparing standard surgical treatment with Mohs micrographic surgery (MMS) or randomized controlled trials comparing surgery with and without adjuvant RT. The type of treatment in our series was MMS with adjuvant RT in 5 cases and MMS alone in 3 cases. The study of Solares et al. [23] is noteworthy because they treated with wide excision combined with adjuvant RT. When MMS was applied, the mean number of surgical steps necessary for complete tumor removal was between two and five (table 2) [23]. However, in most publications the number of interventions was not mentioned. In publications with larger numbers of patients, the rate of recurrence was higher than in smaller case series (table 2). Thorough radical excision seems to be mandatory. MMS is thought to be superior to standard surgical excision because there is a greater sensitivity to detect PNI and a lower rate of recurrence [24]. Local control rates for SCC with PNI achieved by MMS versus standard excision, with or without postoperative RT, ranged from 92 to $100 \%$ for MMS and from 38 to $87 \%$ for standard excision [3]. Cause-specific survival rates varied from 100 to $64 \%$ (table 2). This may play a role for aPNI to better achieve tumor-free boarders. On the other hand, for patients with cPNI, MRI imaging should be performed prior to surgery since with modern 3T MR neurography techniques the extent of nerve involvement may be seen and surgery planned thereafter. RT in a curative or adjuvant manner is another option. Adjuvant RT can be used for tumor destruction in places difficult to reach (skull base, cranial cavity) or to destroy remaining tumor cells after excision [25]. Its efficacy has not been evaluated so far in SCC with PNI. There is no known randomized controlled trial comparing surgery alone versus surgery combined with adjuvant RT. Since SCC with PNI behaves aggressively, frequent recurrence, metastasis and a poorer prognosis are evident. Due to concerns regarding the reliability of surgical margins, adjuvant RT is advised [25]. Criteria for adjuvant RT are lymph node metastases, positive resection margins, poor differentiation, perivascular invasion and tumor size $>2 \mathrm{~cm}$. Most patients treated with adjuvant RT had SCC with $\mathrm{cPNI}$. The efficacy of surgical excision combined with adjuvant RT was seen to be $38-87 \%$ [3]. Whether adjuvant RT could also be beneficial in patients with SCC with aPNI is not known. Some authors state that patients with aPNI bear a risk of subclinical disease in the regional lymph nodes and therefore favor adjuvant RT $[26,27]$. The choice should be made individually for each patient.

Looking at the data of our patients and at the published literature we think that radiographic imaging and adjuvant RT in cutaneous SCC with PNI may be considered, but only when one or more additional risk factors (male, $>6$ th decade of life, tumor $>2 \mathrm{~cm}$ in diameter, tumor thickness $>5 \mathrm{~mm}$, moderate to poor tumor cell differentiation, clinical symptoms of neuropathy, diameter of nerves involved $\geq 0.1 \mathrm{~mm}$ ) are present. Up to now there are no clinical studies showing an improved outcome for patients undergoing radiographic imaging prior to surgery.

\section{Conclusions}

Recurrent and/or large and/or poorly differentiated cutaneous SCCs often bear a higher risk of PNI. Patients with neurological symptoms and/or positive MRI findings have a poorer prognosis.

Radiographic studies as expected cannot detect aPNI, and although in the past they have missed cPNI, with modern imaging sequences this is becoming far less frequent.

In histology, staining with laminin 5, p75 NGFR and S100, plasminogen activator- 1 and neural cell adhesion molecule can help in identifying PNI.

In aPNI, MMS is recommended as a method superior to standard excision. Radiographic imaging and adjuvant RT may be considered, but only if additional risk factors (male, $>6$ th decade of life, tumor $>2 \mathrm{~cm}$ in diameter, tumor thickness $>5 \mathrm{~mm}$, moderate to poor tumor cell differentiation, clinical symptoms of neuropathy, diameter of nerves involved $\geq 0.1 \mathrm{~mm}$ ) are present, although a higher efficacy has not been proven in controlled trials.

In cPNI, MRI is an option to possibly estimate the extent of infiltrated nerves prior to wide surgical excision, yet there are no evidence-based data proving a benefit for the patients. Surgery should be followed by RT.

Furthermore, we advise frequent and long-term followup in these patients to identify recurrences at an early stage.

\section{Disclosure Statement}

None of the authors has any financial interest concerning this publication. 


\section{References}

$>1$ Breuninger H, Eigentler T, Bootz F, et al: Brief S2k guidelines - cutaneous squamous cell carcinoma. J Dtsch Dermatol Ges 2013;11(suppl 3):37-47.

$>2$ Geist DE, Garcia-Moliner M, Fitzek MM, et al: Perineural invasion of cutaneous squamous cell carcinoma and basal cell carcinoma: raising awareness and optimizing management. Dermatol Surg 2008;34:1642-1651.

3 Reule RB, Golda NJ, Wheeland RG: Treatment of cutaneous squamous cell carcinoma with perineural invasion using Mohs micrographic surgery: report of two cases and review of the literature. Dermatol Surg 2009;35 1559-1566.

4 O'Bryan K, Sherman W, Niedt GW, et al: An evolving paradigm for the workup and management of high-risk cutaneous squamous cell carcinoma. J Am Acad Dermatol 2013;69: 595-602.e1.

5 Cherpelis BS, Marcusen C, Lang PG: Prognostic factors for metastasis in squamous cell carcinoma of the skin. Dermatol Surg 2002; 28:268-273

6 Ernst P: Über das Wachstum und die Verbreitung bösartiger Geschwülste. Beitr Pathol Anat 1905;7:29-51.

7 Buchanan L, De'Ambrosis B, DeAmbrosis K, et al: Defining incidental perineural invasion: the need for a national registry. Australas J Dermatol 2014;55:107-110.

-8 Leibovitch I, Huilgol SC, Selva D, et al: Cutaneous squamous cell carcinoma treated with Mohs micrographic surgery in Australia II Perineural invasion. J Am Acad Dermatol 2005;53:261-266.

$>9$ Lawrence N, Cottel WI: Squamous cell carcinoma of skin with perineural invasion. J Am Acad Dermatol 1994;31:30-33.

10 Goepfert H, Dichtel WJ, Medina JE, et al Perineural invasion in squamous cell skin carcinoma of the head and neck. Am J Surg 1984; 148:542-547.
11 Cottel WI: Perineural invasion by squamouscell carcinoma. J Dermatol Surg Oncol 1982; 8:589-600.

12 Catalano PJ, Sen C, Biller HF: Cranial neuropathy secondary to perineural spread of cutaneous malignancies. Am J Otol 1995;16: 772-777.

13 Ampil FL, Hardin JC, Peskind SP, et al: Perineural invasion in skin cancer of the head and neck: a review of nine cases. J Oral Maxillofac Surg 1995;53:34-38.

14 Lesnik DJ, Boey HP: Perineural invasion of the facial nerve by a cutaneous squamous cell cancer: a case report. Ear Nose Throat J 2004; 83:824, 826-827

15 Panizza B, Solares CA, Redmond M, et al: Surgical resection for clinical perineural invasion from cutaneous squamous cell carcinoma of the head and neck. Head Neck 2012;34:16221627.

16 Lin C, Tripcony L, Keller J, et al: Perineural infiltration of cutaneous squamous cell carcinoma and basal cell carcinoma without clinical features. Int J Radiat Oncol Biol Phys 2012; 82:334-340.

17 Campoli M, Brodland DG, Zitelli J: A prospective evaluation of the clinical, histologic, and therapeutic variables associated with incidental perineural invasion in cutaneous squamous cell carcinoma. J Am Acad Dermatol 2014;70:630-636.

18 Green JS, Tournas JA, Allen EJ, et al: Mohs frozen tissue sections in comparison to similar paraffin-embedded tissue sections in identifying perineural tumor invasion in cutane ous squamous cell carcinoma. J Am Acad Dermatol 2012;67:113-121.
19 Solares CA, Boyle GM, Brown I, et al: Reduced alphaB-crystallin staining in perineural invasion of head and neck cutaneous squamous cell carcinoma. Otolaryngol Head Neck Surg 2010;142(3 suppl 1):S15-S19.

20 Lewis KR, Colome-Grimmer MI, Uchida T, et al: p75(NGFR) immunostaining for the detection of perineural invasion by cutaneous squamous cell carcinoma. Dermatol Surg 2006;32:177-183.

21 Panizza B, Warren TA, Solares CA, et al: Histopathological features of clinical perineural invasion of cutaneous squamous cell carcinoma of the head and neck and the potential implications for treatment. Head Neck 2014;36: 1611-1618.

22 Ross AS, Whalen FM, Elenitsas R, et al: Diameter of involved nerves predicts outcomes in cutaneous squamous cell carcinoma with perineural invasion: an investigator-blinded retrospective cohort study. Dermatol Surg 2009;35:1859-1866.

23 Solares CA, Lee K, Parmar P, et al: Epidemiology of clinical perineural invasion in cutaneous squamous cell carcinoma of the head and neck. Otolaryngol Head Neck Surg 2012;146: 746-751.

24 Feasel AM, Brown TJ, Bogle MA, et al: Perineural invasion of cutaneous malignancies. Dermatol Surg 2001;27:531-542.

25 Han A, Ratner D: What is the role of adjuvant radiotherapy in the treatment of cutaneous squamous cell carcinoma with perineural invasion? Cancer 2007;109:1053-1059.

26 Garcia-Serra A, Hinerman RW, Mendenhall WM, et al: Carcinoma of the skin with perineural invasion. Head Neck 2003;25:10271033.

27 Mendenhall WM, Ferlito A, Takes RP, et al: Cutaneous head and neck basal and squamous cell carcinomas with perineural invasion. Oral Oncol 2012;48:918-922.

-28 Carter JB, Johnson MM, Chua TL, et al: Outcomes of primary cutaneous squamous cell carcinoma with perineural invasion. JAMA Dermatol 2013;149:35-41. 